\title{
Editorial
}

\section{The new direct world and the skills it demands}

Journal of Direct, Data and Digital Marketing Practice (2013) 14, 289-290. doi:10.1057/dddmp.2013.29

\section{Challenger brand or cult?}

If you started your career in direct marketing (DM) 25 years ago, it felt like you were joining a challenger brand at best or an underground cult at worst. The dominant mode of distribution was retail and the principal marketing method was advertising. Believing that you could sell more by using direct-to-customer channels and applying data and analytics to improve targeting and response was looked on as an alternative perspective, rather than a mainstream option.

As one of our special anniversary features points out, changes in the way direct, data and digital marketing are described in the IDM Journal are very revealing about how the industry has evolved over that time. The whitepaper by Richard Webber and Dick Stroud (pp. 310-320) shows that many of the trends that you might have predicted can be found, but they are accompanied by some you might not.

\section{Campaign periods still vital}

As their analysis of previous content demonstrates, the most commonly used terms in the Journal relate to campaigns and their results. Marketing is, if anything, more focused on its ROI than ever, and while the pace of campaign production and delivery has changed brands still need to measure and manage by periods, rather than in an always-on manner.

This can also be seen in the amount of content focused on business information and financial performance. Yet these have also undergone the second steepest decline over the lifetime of the Journal. Webber and Stroud point out that DM used to be considered to be a part of business consultancy, profoundly changing the way a business goes to market and interacts with its customers. That shift could be argued to have taken place and to be embedded in the very digital channels, such as websites and email, which are now taken for granted. All the same, there is a risk that the triumph of DM as a marketing paradigm may also have diluted some of the benefits it ought to be delivering.

\section{DM practices unchanged for a century}

Those who did enter the industry back then had a more constrained world to operate in - only two terrestrial commercial TV stations and one nascent satellite broadcaster, for example, with catalogues, direct mail and off-the-page ads the primary methods of prospecting for customers. Our main article in this edition, written by Richard Webber on the basis of contributions from the Executive Editorial Board, reveals that these were methods that had been practiced for more than a century, since Sears reached out to the American mid-West via mail order.

The pace of change in the last two and a half decades has been more breathless and every new cohort of marketers has been faced with rapid and real alterations to the media landscape. That has implications for the skills set now necessary to operate effectively, something the IDM is very focused on addressing. 


\section{The rise of the digital specialist}

One outcome is that ultra-specialization is now commonplace. The digital marketing function needs experts on search engine optimization (SEO), affiliates, email, online display, website optimization - the list goes on. Data specialists are now very much part of the marketing function, from web analysts and insight managers through to data scientists. Can any one individual encompass all of those? Unlikely. Yet marketing directors and chief marketing officers somehow need to understand a little of everything.

Perhaps the most profound change of all is that marketing itself, driven by digital channels and data insights, has completely jumped the fence. Instead of being an activity that a business turns to once it has developed a product and service and for which it now needs to find a market, marketing permeates the whole enterprise as a constant companion. Who now runs an event without having a social marketing strategy in place, for example? Our case study on pages 321-328 shows how even one of the biggest sporting events on the planet - the Superbowl - now takes into account how marketing is influencing the audience in real time.

\section{Broader responsibility, narrower skills}

Therefore, the business model of DM has triumphed in the digital era. But individuals who describe themselves as direct marketers are now almost impossible to find. When nearly every channel can be targeted, contains its own response channel and yields almost unlimited data, DM no longer looks like a specific activity — rather it is generic. Understanding the breadth of DM's new reach is as challenging as being able to manage the detail of its individual component parts. Resolving that tension may prove to provide the narrative for the next 25 years of this Journal.

David Reed FIDM 